\title{
THE IMPACT OF SOCIAL MEDIA ON THE YOUTH: THE GHANAIAN PERSPECTIVE
}

\author{
${ }^{1}$ Selasi Kwame Ocansey, ${ }^{2}$ Wolali Ametepe and ${ }^{3}$ Charles Fynn Oduro \\ 1,2 Jiangsu University,China(School of Computer Science and Communication Engineering) \\ ${ }^{3}$ Bluecrest University College \\ Email:1mrocansey@msn.com
}

\begin{abstract}
Today's world is a global village. Everyone is connected to one another in this vast network generated by the Internet. As social media sites continue to grow in popularity it promises a lot for the modern youth. Social media has been widely adopted, with high enthusiasm among youth around the world. With very few studies focusing on youth social media use in Ghana there is wide open array of work to be done. Based on the findings of several research studies in social media area, it has been found that these Social networking sites are having a great impact on the lives of young people. Also since most of the research works have been carried out in other countries, it was found necessary and important to carry out a study in Ghana on the impact of Social Media on the youth. The main objectives of this study were to investigate the extent of social media use and the purposes, access and impact of its use by the young people in Ghana. Two hundred youth aged between 15-25 participated in the study.

The findings revealed patterns of young people's social media use consistent with similar studies of youths in other countries. The study revealed the need for young people to have a greater awareness of the risks of social media use. It was found that the majority of Ghanaian youths were using Social media on an enormous scale, mainly for communication purposes. According to this study, although social media has a positive impact on the youth, yet quite a large number of respondents reported having met with negative experiences on these online sites.
\end{abstract}

Keywords: social media, youth, communication, Social networking sites

\section{INTRODUCTION}

Social media is the integration of digital media including combinations of electronic texts, graphics, moving images and sound into a structured computerized(digital) environment that allows people to interact with the data for appropriate purposes. This digital environment includes the internet, telecoms and interactive digital television. In recent times social media sites have become a part of daily routine especially for the youth. Majority of the youth are shifting speedily from electronic media such as television viewers and radio listeners to the social media among all age of group. Youth rate is very much to shifting into social media so it's influences are much on youth.

The last 10 years, the number of youth using social media sites has increased dramatically. According to a recent poll, $22 \%$ of teenagers' log on to their favorite social media site more than 10 times a day, and more than half of adolescents log on to a social media site more than once a day [9].Hinduja et al.[13] in their research showed that $75 \%$ of teenagers own mobile phones, and $25 \%$ use them for social media, $54 \%$ use them for texting, and $24 \%$ use them for instant messaging. These research prove that a large part of this generation's social and emotional development is occurring while on the Internet and on mobile phones. 
Most youth are at some risk as they navigate and experiment with social media because of their limited capacity for self-regulation and vulnerability to peer pressure. The 2016 statistics on African internet usage released by Internet World statistics [16] reveal that 7,958,675 Ghanaians are using the internet and $3,500,000$ use facebook. This represent $13 \%$ of the total population of Ghanaians which is $26,908,262$.

This research seeks to find out what use social media are in the lives of the youth and their implications. With the advent of information Technology (IT) almost everywhere, there has been a dramatic adjustment in the way we live.IT tools such as computers, Tablets and mobile phones have become valued elements in the lives of most Ghanaian youths merely because it aids them to interact and communicate freely. Technology has many positive facets but can become dangerous when in wrong hands. Social media offers several benefits and opportunities to young people, including access to information, extended social networks, social skills practice, identity expression, informal learning opportunities, interest-based groups, development and maintenance of friendships and fun. Social media has been described as an important part of a young person's life and a platform for experimentation, creative self-expression and identity formation.

\section{STATEMENT OF PROBLEM}

Technology has many positive aspects but, in the wrong hands, it can become dangerous. For the young people technology is a tryout to do what they feel is good or exciting to them and their friends. Social media has been described by Cortesi[2] as an important part of a young person's life and a platform for experimentation, creative self-expression and identity formation. The rise in the use of social media by the youth has several threats and consequences. These threats and consequences include privacy concerns such as sharing lot of information, posting of false information about themselves or others, exposure to fraudsters and addictions to Internet or social media use that might impact negatively on their social, psychological, low academic output and emotional well-being [10].

Cyber crime is one of the major issues concerning internet use amongst the youth in Ghana. The crimes include credit card fraud, identity theft, hacking and Dating scams. With the current acquaintance and easy access that the youth are able to get out of these mediums, this study will establish the impacts it has have on the youth in Ghana.

\section{RESEARCH QUESTIONS}

The following research questions guided the study:

1.How do the youth in Ghana use social media in their daily lives?

2.What are the purposes for which they use social media?

3.What are the threats that come with use of social media among the youths in Ghana?

4.How do they access social media?

\section{SIGNIFICANCE OF STUDY}

This study is beneficial to apply social media in the right direction and create awareness among the youth that proper use of social media become a tool to educate, enlighten and coach their mindset level. This study further complements to the knowledge about social media use by youth in Ghana. The findings of this paper will inform government and other stakeholders about trends in young people's social media use and problems related with its use and suggest measures to promote its effective and responsible use. 
INTERNATIONAL JOURNAL OF ENGINEERING TECHNOLOGY AND SCIENCES (IJETS) Vol.6 (1) Dec

2016 DOI: http://dx.doi.org/10.15282/ijets.6.2016.1.12.1062

\section{THEORETICAL FRAMEWORK}

This study uses the Uses and Gratification Theory (UGT). UGT suggests that people actively choose their media based on their specific needs. The driving question of UGT is: Why do people use media and what do they use them for?

UGT discusses how users deliberately choose media that will satisfy given needs and allow one to enhance knowledge, relaxation, social interactions/companionship, diversion, or escape. It assumes that audience members are not passive consumers of media. Rather, the audience has power over their media consumption and assumes an active role in interpreting and integrating media into their own lives.

UGT unlike other theoretical perspectives, holds that audiences are responsible for choosing media to meet their requirements and needs to attain gratification. This theory would then imply that the media compete against other information sources for viewers' gratification. Researchers are presently using this theory to examine the extent of use, motivations and gratifications for the exponential use of new media including social network sites(SNS)[5].A number of studies have applied UGT in investigating social media use. Karimi et al.[5] applied this theory to compare the motivations for use of SNS by highereducation students from Iran, Malaysia, the United Kingdom, and South Africa. Whiting et al.[18] identified ten uses and gratifications related to people's social media use: entertainment, communication, expression of opinions, surveillance/knowledge about others, information sharing, relaxation, social interaction, information seeking, pastime and convenience. Other works has shown that motivations for joining SNS include keeping in touch with friends, getting to know more people, networking, finding academic course information and meeting people with mutual interests. Uses and Gratifications theory is adopted as a theoretical framework for reasons being that it has previously been used successfully to examine the underlying reasons for media use to satisfy particular needs and has also been successfully used to understand consumers' motivations and behaviors in the use of traditional media such as TV and radio.

\section{LITERATURE REVIEW}

Social media(SM) has become an increasing phenomenon with many and varied definitions in public and academic use. Generally Social media can be referred to as the media used to facilitate social interaction. Social media integrates digital media including combinations of electronic texts, graphics, images and sound into a structured computerized environment that allows people to interact with the data for appropriate purposes.SM also contains design elements that create virtual social spaces encouraging interaction, thereby broadening the appeal of the technology and promoting transitions back and forth from the platform to face-to-face engagement. The phrase "social networking sites" (SNS) can be used as an umbrella term for all social media and computer-mediated communication, including but not limited to Facebook, Youtube, Twitter, LinkedIn and Wechat. Hence the terms "social media" and "social network sites" are used interchangeably. Ellison et al. [3](2007) define social network sites as web-based services that allow individuals to create profiles, display user connections, and search and navigate within that list of connections.

SM distinct from the communication functions of other online technologies, has provided a virtual setting mirroring familiar elements of community as we understood and experienced it prior to the existence of such technologies. Social media technology links people together in ways that resemble traditional 
feelings of connection, belonging, loosely defined memberships, exchange of feelings and ideas, and the reporting of experiences and actions. Indeed, some suggest SM has suddenly lowered the costs of collaborating, sharing, and producing, thus providing revolutionary new forms of interaction and problem-solving [14]. We can now create, maintain, and access both well-defined and amorphously defined communities online, while also using the social media technology as a tool to fluidly transition between online and face-to-face contact via friendships, planned activities, and other more formal organizational affiliations.

SM has become a major part of our daily lives and in this way, the boundaries between online and realworld communities are rapidly stretching if not completely fading. Particularly, as we consider the generation for whom such social media exchanges have existed their entire lives, there is an unsolidified interchange between digital and physical experiences. For this generation, SM is a primary means of communication and information seeking, and possibly, a central component of their identity and community building. In their papers [11, 15] suggested that the generation (digital natives) for whom such social media exchanges have existed their entire lives may experience fundamentally different brain development that favors constant communication and multitasking. These digital natives as suggested by Professor of Psychiatry at UCLA, Dr. Gary Small in an interview in 2008 are young people born into a world of laptops and cell phones, text messaging and tweeting. Spend, on average, more than eight hours a day exposed to digital technology. These digital natives as suggested by Professor of Psychiatry at UCLA, Dr. Gary Small in an interview in 2008 are young people born into a world of laptops and cell phones, text messaging and tweeting. They spend on average, more than eight hours a day exposed to digital technology [7].

Tapscott(1998)[17] in his paper talks of growing up in a digital environment referring to the youth as the "Net Generation". Children are socializing in a hybrid virtual space, learning in innovative ways, creating a new language and practicing multicultural values. The main characteristics of the N-Gen culture are: independence, emotional and intellectual openness, inclusion, free expression and strong views, innovative, preoccupation with maturity, pleasure by the investigation, immediacy, and sensitivity to corporate interest, authentication, and trust. Lenhart et al. [6] (2007) in their paper in Adolescent social networking, said that in the past five years social networking has "rocketed from a niche activity into a phenomenon that engages tens of millions of Internet users". The study proposes that online social networking profiles posted by adolescents contain intimate, candid, and observable self-disclosure and peer interaction that can be analyzed creating an overall picture of adolescent behavior, highlighting specific areas needing additional research, and addressing implications for parental monitoring and intervention. Lehnhart and Madden state that the behavior of students, $48 \%$ indicated that they had not been affected by what they saw online, $2.5 \%$ felt that their learning had been positively affected and $23.3 \%$ said that they could not concentrate fully on their studies. Over $70 \%$ of parents answered that their children had become friendlier and their dressing, speech, and reading habits had improved. The negative effects noticed by parents included inappropriate dressing, unorthodox hairstyles, distractions from learning, and use of jargon or Pidgin English by their children. The participants made suggestions on how to mitigate the negative effects of social media. Teachers advocated control of student's social media use and formulating policies to ensure responsible use of social media. Parents suggested that social media be used for academic purposes only, at specific times under parental supervision, with enforcement of censorship in social media use.

\section{METHODOLOGY}

The objective of this study is to find out the usage patterns of SN among youths in Ghana and the impact it has on them. The research has made use of survey method. Survey was conducted among randomly 
selected social networking sites users in Ghana with a sample size of 200 between age group of 15 to 25 years who were school students and university students. The age group 15-25 years was chosen since they are the heavy users of social networking sites and also early adopters of advanced technological applications.

The surveys were done using web where the questionnaire are circulated through e-mail and also some of the data were collected through interview on telephone where the respondents are called over telephone to get a deeper insight and more information regarding the research. Also data were collected through direct conversation in which the questionnaires were distributed directly to the respondents and had face-to-face conversations questioning them to know on the impact, behavioral changes caused on them by the networking sites. The questionnaire was designed to collect demographic information, frequency of SN use, purposes for use of social media, social media preferences, access to social media, effect of social media on developmental needs and problems with social media use. This research also involves observation-both direct and participatory method, where direct observation was done with family members, peers, friends, colleagues which helped knowing some of the facts related to the research. The other method participatory observation was done by being active members in one or more social networking sites and taking part in conversations and by becoming community members. While discussing the topics in forums, observations were made that helped in knowing about the information and facts related to the research.

\section{RESULT}

\subsection{Participants Background}

The participants were asked to indicate their age, gender, educational level. The results (Table 1) show that most of the respondents were males (68\%), between the ages of 23 and 25 (55\%), and attended Tertiary institutions.

Table 1: Summary of Respondents Background

\begin{tabular}{|l|l|l|l|l|}
\hline CATEGORIES & \multicolumn{3}{|c|}{ TOTAL NUMBER N=200 } & \\
\hline Gender & Male(59\%) & Female(41\%) & & \\
\hline Age Groups & $15-17(34 \%)$ & $16-22(11 \%)$ & $23-25(55 \%)$ & \\
\hline Education & $\begin{array}{l}\text { Senior high } \\
\text { school(32\%) }\end{array}$ & Tertiary(68\%) & & \\
\hline
\end{tabular}

\subsection{Social Media Use}

The respondents were questioned to indicate whether they were members on any SN.The results showed that social media is popular among the youth surveyed, where $86 \%$ of respondents had profiles, $7 \%$ did not, and $7 \%$ did not respond. They were asked further to indicate the types of social media they used. The results (Table 2) showed that Facebook and WhatsApp were the most popular SNS among the participants by $93.5 \%$ and $95.0 \%$, respectively. Other SNS used by study participants in descending order were Twitter, YouTube, Skype, Instagram, Snapchat and Google+.

\section{Table 2: Social Media Membership of Respondents}


INTERNATIONAL JOURNAL OF ENGINEERING TECHNOLOGY AND SCIENCES (IJETS) Vol.6 (1) Dec 2016 DOI: http://dx.doi.org/10.15282/ijets.6.2016.1.12.1062

\begin{tabular}{|l|c|c|}
\hline \multicolumn{3}{|c|}{ TOTAL NUMBER N=2OO } \\
\hline CATEGORIES & Number of Users & Percentage \\
\hline Facebook & 187 & $93.5 \%$ \\
\hline Whatsapp & 190 & $95.0 \%$ \\
\hline Twitter & 63 & $31.5 \%$ \\
\hline Youtube & 145 & $72.5 \%$ \\
\hline Skype & 98 & $49.0 \%$ \\
\hline Instagram & 105 & $52.5 \%$ \\
\hline Snapchat & 88 & $44.0 \%$ \\
\hline Google+ & 51 & $25.5 \%$ \\
\hline
\end{tabular}

8.3 Device(s) Used to access SNS

Respondents were asked what means or what device they use to access SNS. The findings of the study revealed that the respondents accessed social media through various technological devices (Figure 1) including desktop computers (45.8\%), smartphones (72.3\%), laptops (56\%) and tablets (33.9\%).

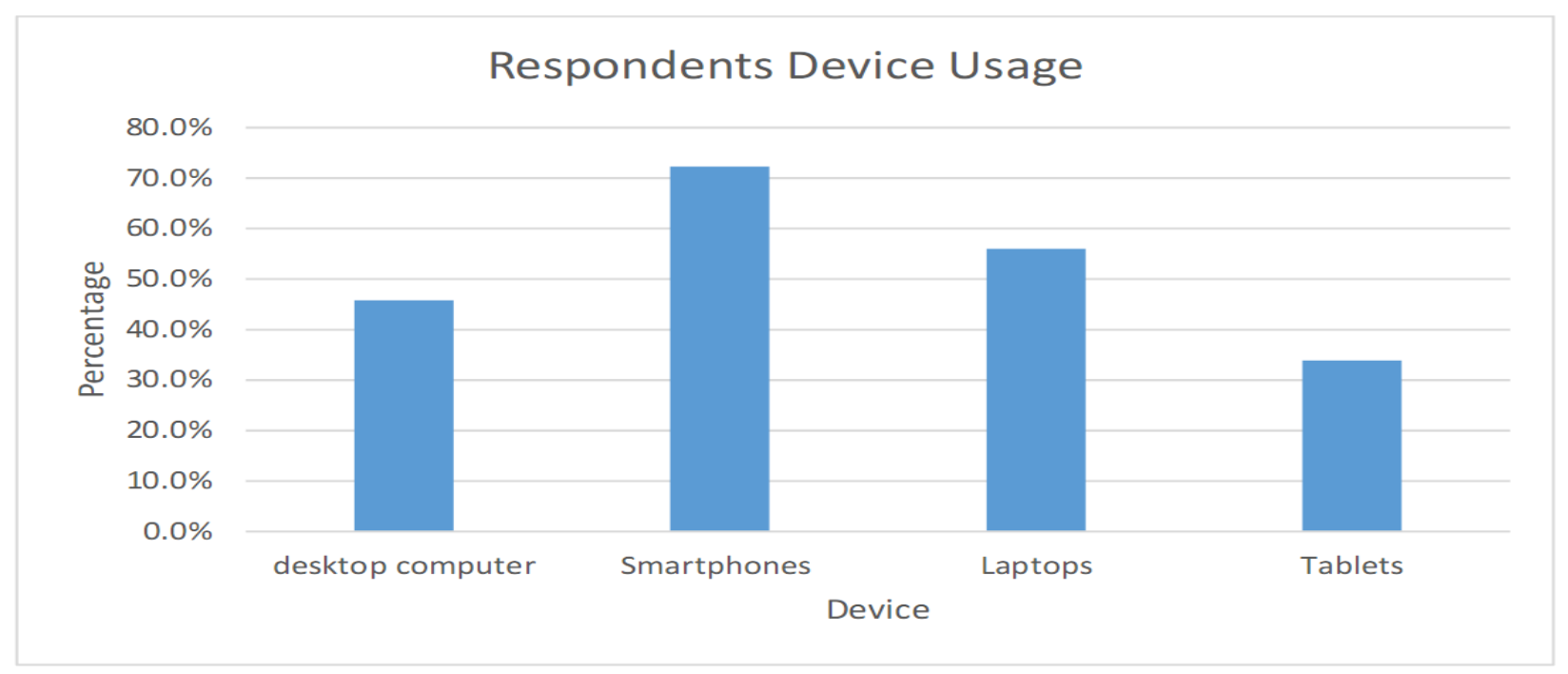

Figure 1: Respondents device usage

\subsection{Purpose of membership on social media}

To determine the uses and gratifications that youth derive from using Social networks, respondents were asked to specify the reasons for which they used social media. Figure 4 show results that the respondents primarily used social media for maintaining contacts, which included messaging and chatting with family members (80\%), old friends (79\%), finding new friends (75\%), dating (45\%) and for business networking (42.6\%). The results showed that a vast majority of respondents are re-establishing existing friends through social networking sites

Table 3: Purpose of membership on social media 
INTERNATIONAL JOURNAL OF ENGINEERING TECHNOLOGY AND SCIENCES (IJETS) Vol.6 (1) Dec 2016 DOI: http://dx.doi.org/10.15282/ijets.6.2016.1.12.1062

\begin{tabular}{|c|c|c|c|}
\hline \multicolumn{4}{|c|}{ Total Number N=200 } \\
\hline \multirow{2}{*}{ Contacts } & $\begin{array}{c}\text { New } \\
\text { Friends:150(75\%) }\end{array}$ & Old Friends:158(79\%) & Fembers:160(80\%) \\
\hline \multirow{2}{*}{ Educational } & $\begin{array}{c}\text { Learning new } \\
\text { topics:36(18\%) }\end{array}$ & $\begin{array}{c}\text { Discussing School related } \\
\text { information:139(69.3\%) }\end{array}$ & $\begin{array}{c}\text { Learn New } \\
\text { Technological } \\
\text { Skills:80(40\%) }\end{array}$ \\
\hline \multirow{2}{*}{ Content Sharing } & $\begin{array}{c}\text { Sending Messages: } \\
112(85.6 \%)\end{array}$ & $\begin{array}{c}\text { Posting/Updating } \\
\text { Profiles:180(90\%) }\end{array}$ & $\begin{array}{l}\text { Posting/Updating } \\
\text { timelines and } \\
\text { status:120(60\%) }\end{array}$ \\
\hline Entertainment & $\begin{array}{c}\text { Listening to } \\
\text { music:136(68\%) }\end{array}$ & Watching Videos:104(52\%) & $\begin{array}{c}\text { Watching } \\
\text { Sports:140(70\%) }\end{array}$ \\
\hline Business & $\begin{array}{c}\text { Shopping Online } \\
: 24(12 \%)\end{array}$ & Networking:85(42.6\%) & \\
\hline
\end{tabular}

while only a marginal number account to using for dating purposes. There were other reasons given by respondents and these included entertainment, such as listening to music (68\%) and watching movies $(52 \%)$ and sports $(70 \%)$; content sharing, such as sending messages $(85.6 \%)$, and posting and updating statuses and timelines (60\%); educational related, such as sharing or discussing school-related information (69.3\%) and learning about new topics of interest (18\%) and new technological skills (40\%) and shopping online (12\%). Connecting with new friends who are deemed strangers in the virtual world has its accompanying set of problems and sometimes it makes them victims of cybercrimes. In terms of business networking there is also a looming danger since there is an uncertainty of the nature of purpose of the individual, reliability, accountability and anonymity leading to serious consequences. Few other text responses made in regard to this question were all accounting to finding old friends, lost contacts such as in school, workplace and among family members as reasons for registering in social networking sites.

\subsection{Rate of Social Media Use}

The participants were asked to indicate the frequency with which they used different SNS, whether they used SNS daily, three times a week or occasionally. Figure 5 show that WhatsApp and Facebook were used much more frequently than the other SNS. 95\% and 44\% of respondents showed they used WhatsApp and Facebook respectively compared to the rest. In terms of the hours spent on SNS each day by the Respondents, the findings showed that $15 \%$ of them spent less than an hour per day, $65 \% 1-5$ hours, 16\% 4-8 hours, and 8\% 7-9 hours per day on SNS. Also 18\% of the respondents spent 15 hours or more a day on social media.

Table 4: Social Media frequency Use 


\begin{tabular}{|l|r|r|r|}
\hline \multicolumn{5}{|c|}{ Total Respondents N=200 } \\
\hline \multicolumn{1}{|c|}{ SNS TYPE } & Daily & thrice Weekly & Occasionally \\
\hline Whatsapp & $95 \%$ & $4 \%$ & $20 \%$ \\
\hline Youtube & $40 \%$ & $30 \%$ & $50 \%$ \\
\hline Twitter & $15 \%$ & $5 \%$ & $45 \%$ \\
\hline Facebook & $84 \%$ & $75 \%$ & $15 \%$ \\
\hline Instagram & $60 \%$ & $35 \%$ & $12 \%$ \\
\hline Snapchat & $55 \%$ & $15 \%$ & $38 \%$ \\
\hline Googe+ & $10 \%$ & $5 \%$ & $15 \%$ \\
\hline Skype & $40 \%$ & $50 \%$ & $40 \%$ \\
\hline
\end{tabular}

\subsection{Gratification of Developmental Needs}

The Uses and Gratification theory indicates that people's choice of media is highly influenced by their needs and the satisfaction they get by using them. Also social media has been associated with several benefits for youth development, such as creative self-expression, identity formation, development and maintenance of new relationships. Respondents were asked point out the types of developmental needs that had their use of social media has satisfied. The majority of the respondents as shown in Table 5 indicated that their friendship needs (78.6\%) had been met, followed by social relationships need (69\%), need to learn and discover new ideas (48\%), and need for family attachment (37\%).

A less number of respondents indicated that their self-expression needs, acceptance by their peers, love and affection, shown recognition (self-esteem), able to freely express negative thoughts have been met by their use of social media.

Table 5: Satisfaction of Needs

\begin{tabular}{|l|c|c|}
\hline \multicolumn{2}{|c|}{ Total Number N=200 } \\
\hline Activity & Frequency & Percentage \\
\hline Friendship & 157 & $78.5 \%$ \\
\hline Acceptance by Peers & 74 & $37.0 \%$ \\
\hline Social Relationship & 184 & $92.0 \%$ \\
\hline Self expression & 138 & $69.0 \%$ \\
\hline Love and Affection & 145 & $72.5 \%$ \\
\hline Learn and discover new ideas & 113 & $56.0 \%$ \\
\hline Self-esteem & 96 & $48.0 \%$ \\
\hline Expreesing negative feelings & 85 & $42.5 \%$ \\
\hline
\end{tabular}

\subsection{Problems Encountered in Using Social Media}

Young social media users encounter some vulnerabilities and risk online hence the study also pursued to find out whether participants of the study had similar or different encounters while using social media. The results show that the main problems (Table 6) indicated by the respondents are cost of internet data 
INTERNATIONAL JOURNAL OF ENGINEERING TECHNOLOGY AND SCIENCES (IJETS) Vol.6 (1) Dec 2016 DOI: http://dx.doi.org/10.15282/ijets.6.2016.1.12.1062

(59.3\%), lack of concentration at school (49\%), sleep deprivation (70\%), unwanted friendship requests $(69 \%)$ and lack of Internet access (45\%).

Table 6: Problems Encountered in Using Social Media

\begin{tabular}{|c|r|}
\hline \multicolumn{2}{|c|}{ Total Participant N=200 } \\
\hline Problems Ecountered & Frequency \\
\hline cost of internet data & $59.3 \%$ \\
\hline lack of concentration at school & $49.0 \%$ \\
\hline sleep deprivation & $70.0 \%$ \\
\hline unwanted friendship requests & $69.0 \%$ \\
\hline lack of Internet access & $45.0 \%$ \\
\hline Cyberbullying & $78 \%$ \\
\hline
\end{tabular}

IX. DISCUSSION OF RESULTS

In recent times Social media has become a common media platform for the youth including participants of this study. The results reveal that $85 \%$ of respondents use SNS. This popularity can be ascribed to the many benefits, or uses and gratifications, that youth derive from it, such as building friendships and communicating with friends both offline and online, entertaining themselves, building their own content, exploring their self-identities and developing self-esteem. From our study we found out that young people from poor backgrounds with limited opportunities at home, social media offers great opportunities for personal and educational advancement, and many try to take the best possible advantage of it. The popularity of social media use among the youth of the current study is consistent with the results of other studies. Pew Internet Project report [12] in 2010 indicates that $73 \%$ of online teenagers use social media.

Our findings showed that the preferred social media of participants were Facebook and WhatsApp. This may probably be because participants are using these two media to stay connected with friends, since some study reports reveal that Facebook and WhatsApp are generally popular among young people. Madden et al. [4] in their reports also concluded that $81 \%$ of online teens in the United States maintain profiles on WhatsApp is much cheaper than buying phone units to make calls or send text messages. The participants in the study prefer using WhatsApp more frequently than other SNS due to its free chat and call features.

The findings also reveal that $8 \%$ of the respondents spent 79 hours a day using SNS and that $15 \%$ of them spent over 15 hours. This finding is troubling since most of the participants are students hence spending this much time on SNS will have less available time for schoolwork, which can affect their academic performance. A Ghanaian study of the effects of social media use on school performance reveals that prolonged use leads to reduced time spent on schoolwork and procrastination in completing assignments especially in the tertiary institutions since there are under little or no parental control.

Most youth in our study have encountered some cyberbullying in their use of social media, including offensive or hurtful messages, name-calling in a chat room, fake profiles and spreading of rumors on SNS. cyberbullying when not taken care can affect the self-esteem of any youth and eventually cause depression.

\section{CONCLUSION}


The primary objective of the research undertaken has been to shed light on the evolution of the dominance of social media among the youthful internet users and its eventual impact on them. The findings of this study have shown that social media is popular among the study participants with over $90 \%$ having profiles on social networking sites, especially Facebook and WhatsApp. The patterns in social media use by young people in the study are largely consistent recorded in other studies in relation to popular social media sites, extent of use, purposes for use, mode of access, and problems encountered in using these sites, as well as the many benefits to their development, including self-identity, relationship development and maintenance, acquisition of social, communication and technical skills, and new knowledge.

We conclude that the youth must be educated on better usage of social media so as to minimize time wastage on chatting and other irrelevant engagements that are not of major importance on their lives. Also stakeholders and network providers need to come up with means of filtering information that reaches the young people through social media platforms. This will curtail exposing them to pornographic and other unwarranted materials. To communicate effectively to the youth, we recommend that schools and government agencies should embrace social media as one of their means of communication.

\section{REFERENCES}

[1] Naomi Amofah-Serwaa and Perpetua Dadzie. "Social media use and its implications on child behaviour: A study of basic school in ghana." International Journal of Social Media and Interactive Learning Environments, 3(1):4962, 2015.

[2] Sandra Cortesi. "Youth online: Diversifying social media platforms and practices", http://h2o.law.harvard.edu/text_blocks/2113,2013. Accessed 10 October,2016.

[3] N. B. Ellison, C. Stein eld, and C. Lampe. "The benefits of facebook "friends:" social capital and college students' use of online social network sites". Journal of Computer-Mediated Communication, 12(4):1, 2007.

[4] Madden et al. "Teens, social media, and privacy digital market asia, data pick of the day: Teen usage of whatsapp up 160\% in 2013". Digital Market Asia, http://www.digitalmarket.asia/data-pick-of-theday-teen usage-of-whatsapp-up-160-in-2013// February 24, 2014

[5] Leila Karimi, Rouhollah Khodabandelou, Maryam Ehsani, andMuhammad Ahmad. "Applying the uses and gratications theory to compare higher education students' motivation for using social networking sites: Experiences from iran, malaysia, United Kingdom, and south Africa". Contemporary educational technology, 5(1):53\{72, 2014.

[6] Amanda Lenhart and Mary Madden. Social networking websites and teens: An overview. Pew Internet American Life Project, 2007.

[7] J. Lin, J.Lin. "Research shows that internet is rewiring our brains[online]".UCLA Today, 2008.

[8] S. M. Livingstone and L. Haddon. "Kids online: Opportunities and risks for children". Bristol, U.K: Policy Press, 2009.

[9] Common Sense Media. "Is technology networking changing childhood? A national poll”, 2009. Accessed 10 October,2016. 
INTERNATIONAL JOURNAL OF ENGINEERING TECHNOLOGY AND SCIENCES (IJETS) Vol.6 (1) Dec 2016 DOI: http://dx.doi.org/10.15282/ijets.6.2016.1.12.1062

[10] Gwenn S. OKeee and Kathleen Clarke-Pearson. "The impact of social media on children,adolescents and families". Pediatrics 127, pages 800-804,2011.

[11] M. Prenksy. Digital natives, digital immigrants. On the Horizon, 9(5):1-6,2001.

[12] Pew Internet Research. Social networking fact sheet. Pew Research Center,2014.

[13] Hinduja S and Patchin J. "Offline consequences of online victimization: school violence and delinquency”. J Sch Violence, pages 89-112, 2007.

[14] C. Shirky. Cognitive surplus. New York:Penguin Press, 2010.

[15] G. Small and G. Vorgan. ibrain: "Surviving the technological alteration of the modern mind". HarperCollins Publishers, 2009.

[16] Internet World Stats. Usage and population statistics, 2014. Accessed 10 October,2016.

[17] D Tapscott. "Growing up digital: The rise of the net generation”. New York:McGraw-Hill, 1997.

[18] Anita Whiting and David Williams. Why people use social media: A uses and gratifications approach, 2013. 